\title{
High frequency ventilation
}

Mechanical ventilation at higher than normal frequencies (HFV) enables gas exchange to be achieved with low tidal volumes and peak airway pressures, thus offering the possibility of reducing barotrauma in patients with severe, acute lung disease. The technique was first used experimentally in the late $1960 \mathrm{~s}^{1}$ to minimise fluctuations in intraarterial pressure associated with mechanical ventilation and has now been used for respiratory support in patients with normal and abnormal lungs. The range of frequencies used is $1-40 \mathrm{~Hz}(60-2400$ bpm), the lower range (1-5 Hz) being used predominantly with high frequency positive pressure ventilation (HFPPV), or high frequency jet ventilation (HFJV), and the higher range $(5-40 \mathrm{~Hz})$ with high frequency oscillation (HFO). Although this rather crude categorisation ignores many of the subtle differences in the design of the ventilator and gas delivery systems which may affect their performance, it highlights the essential differences between the three techniques.

In HFPPV an intermittent flow of gas is delivered via a pneumatic or mechanical valve system to an endotracheal tube or insufflation catheter placed in the trachea. Entrainment of additional gas is minimal and expiration is passive. In HFJV the gas is delivered at high velocity from a jet. Entrainment may be significant but is very variable, and expiration is again passive. In both these techniques minute volume is determined by the inspiratory flow rate and the duration of inspiration, so that an increase in frequency results in a reduction in tidal volume. Usually, the inspiratory:expiratory time ratio (Ti/Ttot) can be varied. This is an important consideration since the time for expiration is limited at high frequencies and large increases in lung volume may occur. ${ }^{2}$ In HFO, a sinusoidal pattern of flow is generated by a piston pump, metal bellows or loudspeaker cone, so that inspiration and expiration are usually of equal duration and the pattern of inspiratory and expiratory flow is actively controlled. Since stroke volume is unaffected by frequency, minute volume is increased when frequency is increased.

Address for reprint requests: Professor MK Sykes, Radcliffe Infirmary, Oxford OX2 $6 \mathrm{HE}$.

\section{High frequency positive pressure ventilation}

The early application of this technique was based on two concepts: firstly, that the delivery of gas via an insufflation catheter in the trachea would reduce the effective dead space and so permit the use of smaller tidal volumes; and, secondly, that the inertia of lung tissue would minimise transmission of airway pressure changes to the heart and great veins, provided that the peak pressures were small and of short duration. Experiments in animals showed that normal blood gas tensions could be maintained with small tidal volumes at frequencies of $1-1.67 \mathrm{~Hz}$ with a Ti/Ttot of 15-35\%.' Subsequent studies showed that the technique could also be used in anaesthetised patients. ${ }^{3}$ Further developments led to the use of this technique for bronchoscopy, laryngoscopy, paediatric anaesthesia, and neonatal respiratory care. ${ }^{45} \mathrm{~A}$ trial in 12 patients with adult respiratory distress syndrome, however, showed no convincing benefit over conventional mechanical ventilation. ${ }^{6}$

There have been few detailed studies of gas exchange during HFPPV, since many of the systems do not permit complete separation of inspired and expired gas. In one study on dogs, however, the problem was overcome by using a constant flow generator with mechanical valves and a fixed Ti/Ttot of $30 \%$. Fresh gas was delivered through a rigid tube with an inside diameter of $2 \mathrm{~mm}$, which was placed within an endotracheal tube, the tip of both tubes being about $10 \mathrm{~cm}$ from the carina. The results showed that physiological dead space decreased to about half when frequency was increased from 0.25 to $0.75 \mathrm{~Hz}$, but that there was no further decrease at higher frequencies. As frequency was increased, it was necessary to increase minute volume to compensate for the increased $V_{D} / V_{T}$ ratio, but at frequencies above $1.67 \mathrm{~Hz}$ the available minute volume (about $301 \mathrm{~min}^{-1}$ ) was not sufficient to maintain normal blood gas tensions. At frequencies above $1 \mathrm{~Hz}$ there was an increase in peak and mean airway pressures and oesophageal pressure owing to incomplete emptying of the lungs.? These experiments suggested that at frequencies up to 2 $\mathrm{Hz}$ gas exchange could be predicted according to the principles of conventional respiratory physiology, an observation that has been confirmed by studies in 
patients. ${ }^{89}$ The variation in dead space with frequency, however, appears to be species dependent, the rabbit showing no change in dead space up to 20 $\mathrm{Hz}$, while the dog shows a considerable reduction at frequencies above $8 \mathrm{~Hz}^{10}$

If it is assumed that dead space is constant at 70 $\mathrm{ml}$ in the intubated adult, and alveolar ventilation is maintained at the level required to produce a normal carbon dioxide tension $\left(\mathrm{PCO}_{2}\right)$, it is possible to calculate the peak pressures which would be developed at varying frequencies if the lung emptied completely after each breath. Such calculations show that peak pressures are minimal in the range $1-1.67 \mathrm{~Hz}$ when airway resistance is normal, but that there is a considerable increase in peak pressures at frequencies above $0.83 \mathrm{~Hz}$ when airway resistance is increased to $20 \mathrm{~cm} \mathrm{H}_{2} \mathrm{O}^{1-1} \mathrm{~s}^{-1}$. An increase in end expiratory lung volume also occurs as frequency is increased ${ }^{2}$ and this may further increase peak pressures. The increase in lung volume increases intrathoracic pressure and leads to a fall in cardiac output. There is therefore good theoretical support for the general conclusion that the Ti/Ttot should be about $20 \%$ and that little is gained by using a frequency above $1 \mathrm{~Hz}$." At this frequency the tidal volume may be reduced by about $30 \% .^{12}$

\section{High frequency jet ventilation}

A great deal of clinical experience has now been accumulated with HFJV, based on either fluid logic or electronically controlled ventilators. With the latter inspiration is produced by the opening of a solenoid operated valve connected to a high pressure gas source (usually $200-400 \mathrm{kPa}$ (2-4 atmospheres)). The opening time of the valve may be adjusted from 40 to $500 \mathrm{msec}$, thus providing a $\mathrm{Ti} /$ Ttot of $20-50 \%$ at frequencies of $1-5 \mathrm{~Hz}$. The driving gas is delivered to the patient through a jet (usually $1.0-1.8 \mathrm{~mm}$ in internal diameter), the inspiratory flow rate being determined by the driving pressure, the resistance of the solenoid valve and connecting tubing, and the resistance of the jet. Typical inspiratory flow rates vary from 0.5 to $1.51 \mathrm{~s}^{-1}$, so that maximum minute volumes may reach 40-50 1 $\min ^{-1}$. In most ventilators gas flow through the jet achieves supersonic velocities so that variations in downstream pressure do not affect flow through the jet. The device thus produces a square wave pattern of flow through the jet, although this may be modified by the opening and closing times of the valve (usually $5-10 \mathrm{msec}$ ), and by valve "bounce", which may allow some flow to occur during expiration. The increase in jet flow caused by this leak may cause a considerable increase in minute volume at high frequencies. The major source of variation in the performance of jet ventilators, however, is that the volume of gas reaching the alveoli may differ from the jet volume because of entrainment of ambient gas or spillage of gas from the jet as it enters the endotracheal tube. ${ }^{1314}$ The degree of entrainment depends mainly on airway resistance and the inertia of the lungs and chest wall; it tends to be decreased by a decrease in driving pressure (and therefore jet velocity) and an increase in frequency, Ti/Ttot, or airway resistance..$^{15}$ The clinical implications are: (1) the volume of gas delivered to the alveoli is very variable; (2) alveolar oxygen tension $\left(\mathrm{Po}_{2}\right)$ is governed by both driving gas $\mathrm{PO}_{2}$ and the $\mathrm{PO}_{2}$ of entrained gas; (3) both driving and entrained gas must be humidified to prevent drying of secretions.

The effects of HFJV on gas exchange appear to be similar to those observed during HFPPV, though the jet stream may penetrate further into the airways than the gas from a conventional mechanical ventilator, so that there may be a reduction in the effective anatomical dead space. ${ }^{1}$ Carbon dioxide elimination is most efficient when the jet is placed close to the carina and when the tidal volume is large and the frequency low. As frequency is increased larger minute volumes are required to clear the carbon dioxide production and at higher frequencies lung volume may increase owing to incomplete emptying. The magnitude of this increase can be reduced by decreasing Ti/Ttot, but this then decreases tidal volume. If an increase in lung volume occurs, there may be a reduction in cardiac output associated with the increase in mean airway pressure..$^{16}$ Experiments using artificial dead spaces of different volumes and lengths suggest that at $1-2 \mathrm{~Hz}$ carbon dioxide elimination is determined by the volume of the dead space, whereas at $5 \mathrm{~Hz}$ length rather than volume is the dominant factor (Bourgain JL, Mortimer AJ, and Sykes MK, unpublished observations). This suggests that at high frequencies (when tidal volume may be less than the volume of the conducting airways), carbon dioxide transfer along the airways is accomplished by some mechanism other than bulk flow. Arterial oxygenation is normal when adequate carbon dioxide elimination is achieved, but in patients with abnormal lungs arterial $\mathrm{PO}_{2}$ increases with the increase in mean airway pressure and lung volume. ${ }^{18}$ As with conventional mechanical ventilation, however, cardiac output falls as mean airway pressure is increased; and this may decrease the oxygen delivery to the tissues. Moreover, for a given mean airway pressure mean intrathoracic pressure may be higher during HFJV than during conventional mechanical ventilation because of the incomplete emptying of the alveoli at high frequencies. 
HFJV has been used in many different clinical circumstances. It is of particular value during anaesthesia when an airtight seal with the trachea cannot be achieved-for example, during bronchoscopy, laryngoscopy, or tracheal reconstruction. ${ }^{19-21}$ Its superiority over jet ventilation at normal respiratory frequencies, however, has not yet been proved. There have also been convincing descriptions of a considerable reduction in air leak and improved blood gas tensions when HFJV has been used in patients with a bronchopleural fistula. ${ }^{22}$ Percutaneous transtracheal HFJV has proved life saving on several occasions, but it is important to ensure that a clear pathway for expired gases is maintained to prevent overdistension of the lungs. ${ }^{23}$

HFJV has been used in oleic acid injury to the lungs in dogs, and in patients with the adult respiratory distress syndrome. When conventional mechanical ventilation and HFJV were compared at equal peak and expiratory pressures or mean airway pressures, venous admixture was greater with HFJV. When peak pressures, however, were matched (so that there were higher mean pressures with HFJV), oxygenation was better with HFJV. As might have been expected, the higher mean airway pressures resulted in a greater fall in cardiac output, thereby partially negating the effect of the reduced venous admixture on oxygen delivery to the tissues. ${ }^{24}$

A further possible use of HFJV is in weaning patients from conventional ventilators. The gas respired during a spontaneous breath must, however, be adequately humidified. This can be achieved by incorporating the jet within a " $T$ " piece, which receives a bias flow of humidified gas, or by using the Mapleson " $D$ " breathing system with the jet ventilator. ${ }^{25}$

A jet ventilator functions as a pressure generator and therefore is most likely to find its main sphere of use in circumstances in which a leak proof connection to the patient cannot be achieved. It is, however, difficult to judge whether the gas exchange is adequate without using blood gas analysis or a transcutaneous electrode. The response of most carbon dioxide analysers is too slow to follow changes in expired gas composition during HFJV, but a satisfactory end tidal plateau can be developed by switching off the jet ventilator and giving two or three deep breaths at normal frequency. Large minute volumes of gas are required to achieve adequate carbon dioxide elimination, particularly at the higher frequencies. These produce rapid drying of secretions and considerable cooling of the patient. Most commercially available ventilators provide humidity by injecting water into the jet stream. This is usually inadequate and poorly controlled, and a separate system is required for humidification of the entrained gas. Systems are now being developed which will both warm and humidify the inspired gas, but these will not be easy to manufacture or control.

\section{High frequency oscillation}

The successful use of this technique was first reported in 1972.2627 The $20-50 \mathrm{~Hz}$ oscillations were produced by an electromagnetic device attached to a membrane stretched over the large diameter of a cone shaped connection. The small end of the cone was connected to a carbon dioxide absorber and an endotracheal tube; a bias flow of oxygen was delivered to the distal end of the endotracheal tube by a catheter. With this device arterial $\mathrm{PCO}_{2}$ could be reduced from 10 to $5 \mathrm{kPa}$ (75 to $38 \mathrm{~mm} \mathrm{Hg}$ ) in less than 15 minutes, while arterial $\mathrm{Po}_{2}$ stayed at about $40 \mathrm{kPa}(300 \mathrm{~mm} \mathrm{Hg})$. Progressive non-respiratory acidosis and a fall in cardiac output during the experiments was probably associated with increased end expiratory pressure; but there was no histological evidence of lung tissue damage. ${ }^{28}$

In 1980 workers in Toronto reported that oscillations at $15 \mathrm{~Hz}$ could produce adequate gas exchange in both the dogs ${ }^{29}$ and man. ${ }^{30}$ The oscillations were produced by a piston pump, and in patients the bias flow of $12-15 \mathrm{l} \mathrm{min}^{-1}$ of oxygen was admitted to the circuit between the pump and the endotracheal tube. The exit port for this gas was connected to a long, thin tube that had a low resistance to continuous flow (thus permitting the bias flow of fresh gas to escape) but a high impedance to the high frequency oscillations. This arrangement permitted the system to be flushed with fresh gas, but resulted in the loss of half to two thirds of the stroke volume emanating from the piston. The oscillation of 12 patients in the intensive care unti with stroke volumes of 50 $150 \mathrm{ml}$ at $15 \mathrm{~Hz}$ resulted $\mathrm{m}$ normal $\mathrm{PCO}_{2}$ values, a small reduction in intrapulmonary shunt, and no change in cardiac output.

Although these studies suggested that adequate gas exchange could be achieved with tidal volumes less than the dead space, there was no measure of the actual volume entering and leaving the lung. By modifying the circuit, however, so that fresh gas was admitted at a flow of $50-601 \mathrm{~min}^{-1}$ from a high pressure source (and aspirated from the circuit at the same rate) other workers were able to ensure that there was no net loss or gain from the bias flow during oscillation, so that tidal volumes could be recorded with a specially calibrated pneumotachograph placed between the piston pump and the bias flow " $T$ " piece. It was concluded that carbon dioxide elimination was most closely related to the product of oscillation volume and frequency, but that there 
was an appreciable variation in the individual contributions of these two variables in dogs. ${ }^{31}$ In patients, on the other hand, it appeared that carbon dioxide elimination was most strongly related to the product of frequency and tidal volume below a frequency of $3.33 \mathrm{~Hz}$, but that above this frequency carbon dioxide output was dependent on tidal volume and independent of frequency..$^{32}$

An interesting pointer to a possible future role of HFO has been provided by a comparison of conventional mechanical ventilation and HFO in a lung lavage model of hyaline membrane disease in rabbits. ${ }^{33}$ These studies showed that after a deep breath arterial $\mathrm{PO}_{2}$ was better maintained and the mortality rate less in the group of rabbits treated with HFO, while histological examination showed minimal lung damage in the HFO group, but appreciable hyaline membrane formation in the group submitted to conventional mechanical ventilation. It was suggested that the rabbits in the HFO group were maintained on the descending limb of the P-V curve, so that lung volumes were higher for a given transpulmonary pressure, and that the small tidal volumes resulted in fewer intraregional stresses than in the conventional mechanical ventilation group. Similar experiments in primates have not, however, confirmed these results. ${ }^{34}$

\section{Mechanisms of gas exchange during HFO}

There is now no doubt that adequate carbon dioxide elimination and oxygen transfer can be achieved during HFO when tidal volumes are less than the volume of the conducting airways. Possible mechanisms have recently been reviewed in detail. ${ }^{3536}$ There appear to be five major modes of transport: (1) direct alveolar ventilation of the lung units situated near the upper airways; (2) convective mixing in the conducting airways as a result of recirculation of air among lung units with differing time constants; (3) convective transport of gases resulting from the asymmetry between the inspiratory and the expiratory flow profiles; (4) longitudinal dispersion from interaction between the axial stream and radial dispersion due to turbulence; (5) molecular diffusion in the alveolar capillary membrane region.

Although the relative importance of these mechanisms cannot be quantified, there is no doubt that convective transport within the tracheobronchial tree still remains very important during HFO. Thus increased tidal volume is more effective than increased frequency in improving gas exchange.

\section{Constant flow ventilation and external vibrations}

One group of workers used jet ventilation at very high frequencies and found that this was only effec- tive if the jets were provided by two orifices placed at the bifurcation of the trachea. ${ }^{37}$ It now appears likely that under these circumstances carbon dioxide removal was mainly due to the streaming of the flow along one side of the major airways. Recently it was shown that a continuous flow of gases delivered into each bronchus at a flow rate of $1-41 \mathrm{~kg}^{-1} \mathrm{~min}^{-1}$ could provide adequate gas exchange in apnoeic dogs for prolonged periods, gas exchange presumably being accomplished by a combination of convection, higher flow separation, asymmetric velocity profiles, augmented dispersion, and possibly cardiogenic oscillations. ${ }^{38}$ Although this technique is interesting, since peak airway pressures are considerably lower than those produced during conventional positive pressure ventilation or HFO, there are no data on the long term effects and there would be problems in humidifying and warming the large flow rates required in man.

Another technique which has been attempted is the external oscillation of the thorax. This has been shown to produce results identical to those of HFO when applied to the trachea in cats and rats. ${ }^{39}$ There are obvious technical difficulties, however, in applying this technique in man.

\section{Conclusions}

There are three main drawbacks to HFV. Firstly, the effects on gas exchange are very variable at frequencies above $1-2 \mathrm{~Hz}$. Secondly conditioning of the inspired gas presents technical problems. Thirdly, since intra-alveolar pressure and tidal volumes cannot be measured directly, an external device has to be used for monitoring tidal and lung volume, and transcutaneous electrodes or frequent blood gas measurement to assess the adequacy of gas exchange. Furthermore, the technique may be noisy and the long term effects are still not clearly defined. The technique can certainly produce adequate gas exchange with reduced peak pressures. We must now determine whether reduction in peak pressures has any benefit in treating acute lung disease.

MK SYKES

Nuffield Department of Anaesthetics Radcliffe Infirmary, Oxford

\section{References}

1 Jonzon A, Öberg PÅ, Sedin G, Sjöstrand U. Highfrequency positive-pressure ventilation by endotracheal insufflation. Acta Anaesthesiol Scand Suppl 1971;43:1-43.

2 Rouby JJ. Jet ventilation a haute fréquence: aspects techniques et mecanisme des echanges gazeux dans les insuffisances respiratoires aigues. In: Bourgain JL, Lienhart A, Viars P, eds. Ventilation a haute fréquence. Paris: Librairie Arnette, 1983:123-44. 
3 Heijman K, Heijman L, Jonzon A, Sedin J, Sjöstrand U, Widman B. High-frequency positive-pressure ventilation during anaesthesia and routine surgery in man. Acta Anaesthesiol Scand 1972;16:176-87.

4 Sjöstrand U. Experimental and clinical evaluation of high-frequency positive-pressure ventilation. Acta Anaesthesiol Scand 1977;suppl 64:1-178.

5 Borg U, Eriksson I, Sjöstrand U. High-frequency positive-pressure ventilation (HFPPV): a review based upon its use during bronchoscopy and for laryngoscopy and microlaryngeal surgery under general anesthesia. Anesth Analg 1980;59:594-603.

6 Wattwill LM, Sjöstrand UM, Borg UR. Comparative studies of IPPV and HFPPV with PEEP in critical care patients. 1: A clinical evaluation. Crit Care Med 1983;11:30-7.

7 Chakrabarti MK, Sykes MK. Cardiorespiratory effects of high-frequency intermittent positive-pressure ventilation in the dog. Br J Anaesth 1980;52:475-82.

8 Rouby JJ, Benhamou D, Simonneau G, et al. Factors influencing tidal volume during high-frequency jet ventilation. Anesthesiology 1984;61: A505 (abstract).

9 Sawa T, Ikezono E, Colgan FJ, TenEyck LG. A ventilatory standard for high frequency ventilation. Anesthesiology 1982;57:A462 (abstract).

10 Fletcher PR, Epstein RA. Species dependence of tidal volume requirements during HFV. Anesthesiology 1984;61:A504 (abstract).

11 Sjöstrand UH, Eriksson IA. High rates and low volumes in mechanical ventilation-not just a matter of ventilatory frequency. Anesth Analg 1980;59:567-75.

12 Sjöstrand U. High-frequency positive-pressure ventilation: a review. Crit Care Med 1980;8:345-64.

13 Bourgain JL, Deriaz H, Sykes MK, Mortimer AJ, Viars P. Essai de modelisation du volume courant delivre en JVHG. In: Bourgain JL, Lienhart A, Viars $\mathrm{P}$, eds. Ventilation a haute fréquence. Paris: Librairie Arnette, 1983:23-43.

14 Davey AJ, Lay GR, Leigh JM. High-frequency jet ventilation. A functional analysis of the Penlon Nuffield Series 200 ventilator. Anaesthesia 1982;37:675-9.

15 Rouby JJ, Benhamou D, Simonneau G, et al. Factors influencing tidal volume during high-frequency jet ventilation. Anesthesiology 1984;61: A505 (abstract).

16 Gallagher TJ, Klain MM, Carlon GC. Present status of high-frequency ventilation. Crit Care Med 1982;10: 613-7.

17 Fusciardi J. Repercussions hemodynamiques de la jet ventilation a haute frequence. In: Bourgain $\mathrm{JL}$, Lienhart A, Viars P, eds. Ventilation a haute fréquence. Paris: Librairie Arnette, 1983:167-86.

18 Rouby JJ, Fusciardi J, Bourgain JL, Viars P. Highfrequency jet ventilation in postoperative respiratory failure: determinants of oxygenation. Anesthesiology 1983;59:281-7.

19 Babinski M, Smith RB, Klain M. High-frequency jet ventilation for laryngoscopy. Anesthesiology 1980; 52:178-80.

20 Vourc'h G, Fischler M, Michon F, Melchior JC, Seigneur $F$. Manual jet ventilation $v$. high frequency jet ventilation during laser resection of tracheo-bronchial stenosis. Br J Anaesth 1983;55:973-5.

21 Smith RB. Ventilation at high respiratory frequencies. High frequency positive pressure ventilation, high frequency jet ventilation and high frequency oscillation. Anaesthesia 1982;37:1011-8.

22 Carlon GC, Ray C, Klain M, McCormack PM. High- frequency positive-pressure ventilation in management of a patient with bronchopleural fistula. Anesthesiology 1980;52:160-2.

23 Klain M, Smith RB. High frequency percutaneous transtracheal jet ventilation. Crit Care Med 1977; 5:280-7.

24 Schuster DP. Klain M. Snyder JV. Comparison of high frequency jet ventilation to conventional ventilation during severe, acute respiratory failure in humans. Crit Care Med 1982;10:625-30.

25 Whitwam JG, Chakrabarti MK, Konarzewski WH, Askitopoulon $H$. A new valveless all-purpose ventilator. Clinical evaluation. $\mathrm{Br} J$ Anaesth 1983; 55:1017-23.

26 Lunkenheimer PP, Rafflenbeul W, Keller H, Frank I, Dickhut HH, Fuhrmann C. Application of transtracheal pressure oscillations as a modification of "diffusion respiration". Br J Anaesth 1972;44:627.

27 Lunkenheimer PP, Frank I, Ising H, Keller H, Dickhut $\mathrm{HH}$. Intrapulmanaler gaswechsel unter simulierter Apnoe durch transtrachealen periodischen intrathorakalen Druckwechsel. Der Anaesthesist 1973; 22:232-8.

28 Frank I, Noack W, Lunkenheimer PP, et al. Light and electron microscopic investigations of pulmonary tissue after high-frequency positive-pressure ventilation (HFPPV). Der Anaesthesist 1975;24:171-6.

29 Bohn DJ, Miyasaka K, Marchak BE, Thompson WK, Froese AB, Bryan AC. Ventilation by high-frequency oscillation. J Appl Physiol: Respir Environ Exercise Physiol 1980;48:710-6.

30 Butler WJ, Bohn DJ, Bryan AC, Froese AB. Ventilation by high-frequency oscillation in humans. Anesth Analg 1980;59:577-84.

31 Slutsky AS, Kamm RD, Rossing TH, et al. Effects of frequency, tidal volume, and lung volume on $\mathrm{CO}_{2}$ elimination in dogs by high frequency $(2-30 \mathrm{~Hz})$, low tidal volume ventilation. J Clin Invest 1981;68:147584.

32 Rossing TH, Slutsky AS, Lehr JL, et al. Tidal volume and frequency dependence of carbon dioxide elimination by high-frequency ventilation. $N$ Engl J Med 1981;305:1375-9.

33 Hamilton PP, Onayemi A, Smyth JA, et al. Comparison of conventional and high-frequency ventilation, oxygenation, and lung pathology. J Appl Physiol: Respir Environ Exercise Physiol 1983;55:131-8.

34 Truog WE, Standaert TA, Murphy JH, Woodrum DE, Hodson WA. Effects of prolonged high-frequency oscillatory ventilation in premature primates with experimental hyaline membrane disease. Am Rev Respir Dis 1984;130:76-80.

35 Chang HK. Mechanisms of gas transport during ventilation by high-frequency oscillation. J Appl Physiol: Respir Environ Exercise Physiol 1984;56:553-63.

36 Drazen JM, Kamm RG, Slutsky AS. High-frequency ventilation. Physiol Rev 1984;64:505-43.

37 Baum M, Benzer H, Geyer A, Hiader W, Mutz N. Forcierte diffusions ventilation (FDV). Der Anaesthesist 1980;29:586-91.

38 Lehnert BE, Oberdörster G, Slutsky AS. Constantflow ventilation of apneic dogs.J Appl Physiol: Respir Environ Exercise Physiol 1982;53:483-9.

39 Harf A, Bertrand C, Chang HK. Ventilation by highfrequency oscillation of thorax or at trachea in rats. $J$ Appl Physiol: Respir Environ Exercise Physiol 1984;56: 155-60. 